We thank Sir Richard Doll, Dr. M. C. Pike, Dr. M. P. Vessey, Dr. L. J. Kinlen, and Mr. R. Peto for their helpful advice. We thank the director, Dr. J. Howlett, and the staff of the Science Research Council's Atlas Computing Laboratory for the provision of computer facilities. We also thank Gale Mead, Catherine Harwood, and Vivienne Williams for typing the manuscript.

\section{References}

Armitage, P. (1966). Fournal of the Royal Statistical Society 'B', 28, 150 Cox, D. R. (1970). Analysis of Binary Data. London, Methuen.

Doll, R., and Hill, A. B. (1954). British Medical fournal, 1, 1451.

Doll, R, and Hill, A. B. (1964). British Medical fournal, 1, 1399, 1460 Goldsmith, J. R. (1970). Annals of the New York Academy of Sciences, 174,122

Hammond, E. C. (1972). In Proceedings of the Second World Conference on Smoking and Health, London, 1971, ed. R. G. Richardson, London, Smoking
Hellung-Larsen, P., Kjeldsen, K., Mellemgaard, K., and Astrup, P. (1966) Scandinavian fournal of Laboratory Investigation, 18, 4443.

Kannel, W. B., Dawber, T. R., Friedman, G. D., Glennon, W. E., and McNamara, P. M. (1964). Annals of Internal Medicine, $61,888$.

Kannel, W. B., Castelli, W. P., and McNamara, P. M. (1967). Fournal of Occupational Medicine, 9,611 .

Kjeldsen, K. (1969). Smoking and Atherosclerosis. Copenhagen, Munksgaard.

Kjeldsen, K., Astrup, P., and Wanstrup, J. (1972). Atherosclerosis, 16, 67.

Lawther, P. J., and Commins, B. T. (1970). Annals of the New York Academy of Sciences, 174, 135.

Miettinen, O. S. (1970). Biometrics, 26, 75

Richterich, R. (1965). Klinische Chemie. Theorie und Praxis, p. 231. Basel, Korge.

Roughton, F. J. W., and Root, W. S. (1945). American fournal of Physiology, 145,239 .

Webster, W. S., Clarkson, T. B., and Lofland, H. B. (1970). Experimental and Molecular Pathology, 13, 36.

Wynder, E. L., and Hoffman, D. (1967). Tobacco and Tobacco Smoke. Studies in Experimental Carcinogenesis, p. 730. New York, Academic Press.

\title{
Double-blind Trial of Linoleate Supplementation of the Diet in Multiple Sclerosis
}

\author{
J. H. D. MILLAR, K. J. ZILKHA \\ M. J. S. LANGMAN, \\ H. PAYLING WRIGHT, A. D. SMITH, \\ J. BELIN, R. H. S. THOMPSON
}

British Medical fournal, 1973, 1, 765-768

\section{Summary}

Seventy-five patients in London and Belfast with multiple sclerosis were given daily supplements of a vegetable oil mixture containing either linoleate or oleate for two years in a double-blind control trial. Relapses tended to be less frequent and were significantly less severe and of shorter duration in the linoleate-supplemented group than in those receiving the oleate mixture, but clear evidence that treatment affected the overall rate of clinical deterioration was not obtained.

\section{Introduction}

There have been several reports of changes in the relative proportions of saturated and unsaturated fatty acids in the brain lipids in multiple sclerosis (Gerstl et al., 1961; Baker et al., 1963; Cumings et al., 1965; Arnetoli et al., 1969; Clausen and Hansen, 1970; Gerstl et al., 1970; Alling et al., 1971) and also that the serum linoleate level is reduced in this desease (Baker et al., 1964; Tichy et al., 1969; Mahler, 1971). The

Department of Neurology, Royal Victoria Hospital, Belfast BT12 6BA J. H. D. MILLAR, M.D., F.R.C.P., Consultant Neurologist

National Hospital, Queen Square, London WC1

K. J. ZILKHA, M.D., F.R.C.P., Consultant Physician

Department of Medicine, General Hospital, Nottingham NG1 6HA M. J. S. LANGMAN, M.D., M.R.C.P., Consultant Physician and Professor of Therapeutics

Department of Pharmacology, Royal College of Surgeons, London WC1

H. PAYLING WRIGHT, PH.D., L.M.S.S.A., Member of External Staff, M.R.C. Thrombosis Research Ünit

Courtauld Institute of Biochemistry, Middlesex Hospital Medical School, London W1P 5PR

A. D. SMITH, B.SC., PH.D., Senior Lecturer in Biochemistry

A. BELIN, M.SC., Research Associate

J. H. S. THOMPSON, F.R.C.P., F.R.C.PATH., Professor of Biochemistry and Director of the Courtauld Institute percentage of linoleate in the phospholipids of platelets and erythrocytes is also significantly reduced in patients with multiple sclerosis (Gul et al., 1970). The possible significance of these biochemical abnormalities in relation to the pathogenesis of the disease has recently been discussed by Thompson (1973).

The view has also been put forward that the geographical incidence of multiple sclerosis and its higher prevalence in some parts of the world may be related to the amount of fat in the diet (Swank, 1950), and in particular to a deficiency of polyunsaturated fatty acids (Sinclair, 1956; Allison, 1963).

Supplementation of diets with linoleate is known to lead in healthy persons to an increase of linoleate in the serum lipid fractions together with a decrease of oleate and sometimes of palmitate, palmitoleate, and stearate. It has recently been shown that patients with multiple sclerosis are able to absorb linoleate from sunflower seed oil supplements as efficiently as healthy control subjects, as is shown by the similar increases in the serum linoleate levels produced in the two groups of subjects (Belin et al., 1971).

Since 1962 one of us (K.J.Z.) has given sunflower seed oil by mouth to 90 patients with multiple sclerosis, and the impression was gained that the clinical course of the disease was improved. Since these observations were uncontrolled, and since multiple sclerosis is a disease in which the clinical course is unpredictable, it was decided to conduct a double-blind trial jointly in London and Belfast in order to determine whether the oral administration of linoleate, taken in the form of daily doses of a sunflower seed oil emulsion, influenced the course of the disease.

After the trial had begun Swank (1970) gave an account of his experience in treating patients with multiple sclerosis over a 20-year period with a regimen involving a reduction of the saturated animal fats and a supplementation of the diet with unsaturated vegetable oils. Although his observations were also uncontrolled he concluded that "patients who consumed the least amount of fat and the largest amounts of fluid oils deteriorated less than those who consumed more fat and less oil."

A further change in the blood of multiple sclerosis patients is shown by the increased adhesiveness to glass of the platelets (Caspary et al., 1965; Payling Wright et al., 1965; Millar et al., 1966; Millac, 1967). This led us to study the platelet adhesive- 
ness of patients on the linoleate and oleate supplements to determine whether it altered with the regimen and also whether platelet changes were associated with clinical relapses.

\section{Methods}

Eighty-seven patients with multiple sclerosis-54 in Belfast and 33 in London-were admitted to the trial, which was carried out separately in the two cities. The patients were allocated at random to "treated" and "control" groups (see below) according to a prearranged schedule. Only patients who could walk, with or without aid (Kurtzke disability status 0-6), were admitted to the trial, but no other restrictions to selection were applied except that all were at a clinically inactive phase of the disease at the start and any patients who had already taken sunflower seed oil were excluded.

Two doses of an oil mixture were taken each day, morning and evening, for a period of two years. For the treated group each dose consisted of $30 \mathrm{ml}$ of a sunflower seed oil emulsion providing $8.6 \mathrm{~g}$ of linoleic acid. The control group received two daily doses of an emulsion similar in appearance and with the same flavouring but containing olive oil in place of the sunflower seed oil; each $30 \mathrm{ml}$ dose of this emulsion provided $3.8 \mathrm{~g}$ of oleic acid (a non-essential fatty acid which can be synthesized by the body from saturated fatty acids) and $0.2 \mathrm{~g}$ of linoleic acid. The sunflower seed oil emulsion was made up as follows: sunflower seed oil $50 \% \mathrm{v} / \mathrm{v}$, methylcellulose $1.4 \% \mathrm{w} / \mathrm{v}$, citric acid $0 \cdot 18 \%$ $\mathrm{w} / \mathrm{v}$, saccharin sodium $0.02 \% \mathrm{w} / \mathrm{v}$, benzoic acid solution $2 \% \mathrm{v} / \mathrm{v}$, orange flavour $0.4 \% \mathrm{v} / \mathrm{v}$, colouring $0.02 \% \mathrm{w} / \mathrm{v}$, and water to $100 \%$. The constituents of the olive oil emulsion were identical with those of the sunflower seed oil emulsion except that in place of the sunflower seed oil olive oil $15 \% \mathrm{v} / \mathrm{v}$ was used and the proportion of methylcellulose was $3.4_{\%}^{\circ} \mathrm{w}_{i}^{\prime} \mathrm{v}$.

Neurological Assessment.-Patients were seen at intervals of two to three months and the severity of the disease at each visit was determined by reference to the Kurtzke (1961) scoring method as modified by Millar et al. (1967). By this method separate assessments were made of the pyramidal, cerebellar, brain stem, sensory, bladder and bowel, visual, mental, and other functions. The disability status was assessed from these separate scores and from the patient's ability to cope with ordinary day-to-day tasks. Relapses were scored separately and points were given per week or per part of a week for the severity and duration of each relapse lasting more than 24 hours reported by the patients when interviewed (table I), as described by Millar et al. (1967). A relapse was not scored after 12 weeks, as by that time a change would be evident on the Kurtzke score card. Mean relapse scores were calculated for each treatment group, but the statistical difference of the findings was assessed by the use of non-parametric ranking tests, so that any undue

TABLE I-Scores used for assessing Severity of Relapses Paraesthesiae or dysaesthesiae Weakness, clumsiness, or ataxi Retention of urine

Other urinary or rectal symptoms Vertigo, facial pain, oculomotor paresis, dysarthria, dvsphagia, or anosmia Dancing vision Retrobulbar neuritis .
1 per limb per week 3 per limb per week 4 per week

3 per week 1 per week 2 per week 3 per eye per week contribution by large scores from single patients with frequently relapsing disease could be to some extent minimized. In addition to clinical scoring venous blood samples were taken at most visits for measurement of platelet adhesiveness and (in London) for measurements of serum fatty acid levels, the results being withheld from the clinicians conducting the trial.

Platelet Adhesiveness.-Platelet adhesiveness was determined by the rotating bulb method (Wright, 1941), modified by the use of $3.1 \%$ trisodium citrate in $9 / 1$ dilution instead of heparin. Platelet counts were made on the initial sample and after 20 minutes of rotation. The count after rotation was expressed as a percentage of the initial one.

Serum Fatty Acid Levels. - The method of extraction and gas-chromatographic estimation of the serum total fatty acids was as described previously (Belin et al., 1971). The estimations were done without knowing to which group the patients belonged.

\section{Results}

Of the 87 patients admitted to the trial 12 dropped out after varying periods of time ( 7 on linoleate and 5 on oleate supplements), 10 owing to failure to attend the clinic for examination and 2 owing to failure to take the supplements. Details of comparability of the 75 patients in the treated and control groups who completed the trial are given in table II in respect of age, sex, and severity and duration of the disease. There were no substantial variations except that the duration of the disease was longer in the treated than in the control group in London.

The clinical results of the trial are summarized in table III. The disability status deteriorated from 2.7 at the start to 3.3 at the end of the trial in the oleate group, and from 2.9 to 3.1 in the linoleate group; this difference between the groups was due to a marked trend at one centre (Belfast), but with a reverse trend at the other centre, so that the overall difference was not significant. The total number of relapses suffered by the 36 patients taking linoleate was 41 over the two years of the trial, whereas the figure for the 39 patients taking the oleate supplements was 62. The types of relapses experienced by the two groups are shown in table IV and the duration in table V. The rate of relapse per patient-year was 0.54 for the linoleate group and 0.76 for the oleate group; this difference is not statistically significant and is due in large part to the presence of a small number of patients in the control group who suffered multiple relapses.

The severity of the relapses, however, differed markedly between the treated and control groups at both centres; relapses were about twice as severe in the oleate-treated group as in those receiving linoleate and were of longer duration. The difference in severity as assessed by a non-parametric ranking test was significant in London and at both centres when considered together $(P<0.01$ in each case), although in Belfast a $P$ value of 0.1 was obtained for the difference between the control and treated groups.

Platelet Adhesiveness.-The observations on platelets confirmed again that their adhesiveness is greater in multiple sclerosis than in normal subjects studied previously (Sanders et al., 1968). Serial observations made on the patients during the course of the trial showed no changes that were of significance and are therefore not considered further.

\begin{tabular}{|c|c|c|c|c|c|c|}
\hline & \multicolumn{2}{|c|}{ Belfast } & \multicolumn{2}{|c|}{ London } & \multicolumn{2}{|c|}{ Total } \\
\hline & Control & Treated & Control & Treated & Control & Treated \\
\hline 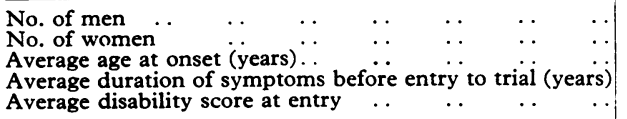 & $\begin{array}{c}8 \\
16 \\
38 \cdot 2 \\
9 \cdot 7 \\
3 \cdot 0\end{array}$ & $\begin{array}{l}10 \\
13 \\
41 \cdot 2 \\
10 \cdot 4 \\
3 \cdot 3\end{array}$ & $\begin{array}{r}6 \\
9 \\
31 \cdot 1 \\
4 \cdot 6 \\
3 \cdot 1\end{array}$ & $\begin{array}{c}6 \\
7 \\
31.7 \\
7 \cdot 0 \\
2 \cdot 0\end{array}$ & $\begin{array}{l}14 \\
25 \\
35 \cdot 5 \\
7 \cdot 7 \\
2 \cdot 7\end{array}$ & $\begin{array}{l}16 \\
20 \\
37 \cdot 8 \\
9 \cdot 2 \\
2 \cdot 9\end{array}$ \\
\hline
\end{tabular}




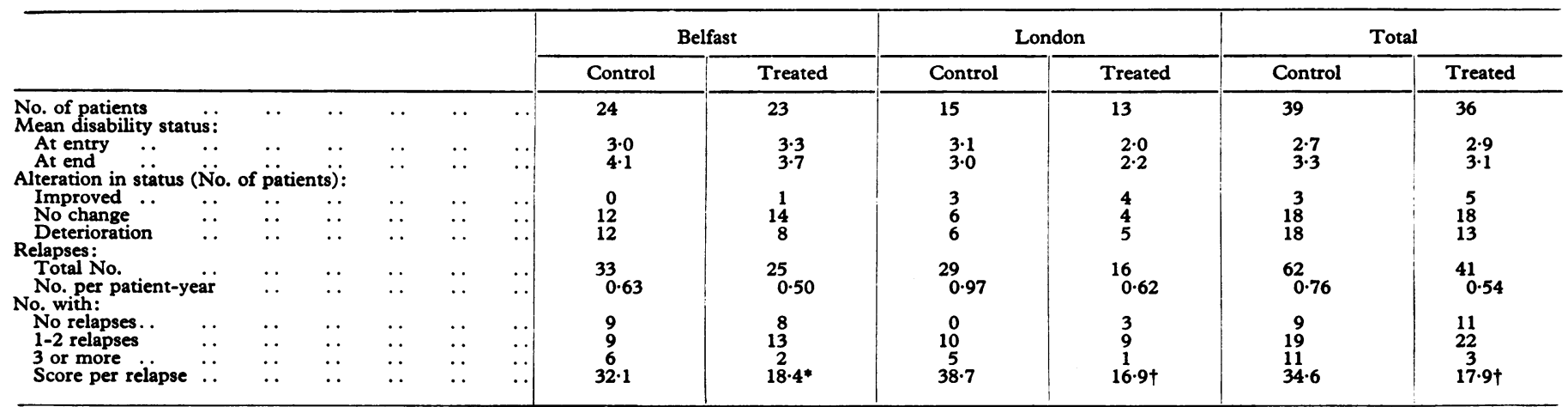

*Control $v$. treated group $\mathbf{P}=0.1$.

tControl v. treated group $P=0.01$.

TABLE IV-Pattern of Relapse Episodes. (Number of Stated Types of Relapse in the Belfast and London Patients combined)

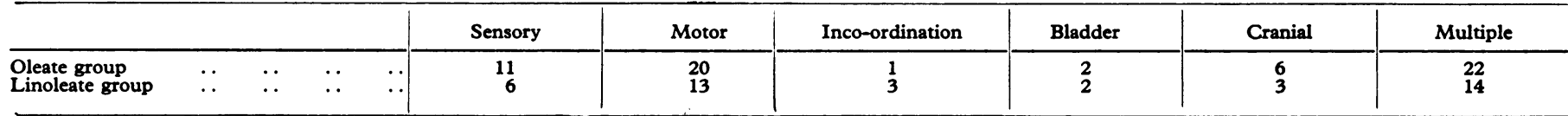

TABLE V-No. and Duration of Relapses

\begin{tabular}{|c|c|c|c|c|}
\hline Duration in weeks: & $1-5$ & $6-9$ & 10 or More & Total \\
\hline $\begin{array}{l}\text { Belfast series: } \\
\text { Controls } \\
\text { Linoleate group } \\
\text { London series: } \\
\text { Controls } \\
\text { Linoleate group }\end{array}$ & $\begin{array}{l}12 \\
17 \\
12 \\
16\end{array}$ & $\begin{array}{r}23 \\
4 \\
15 \\
0\end{array}$ & $\begin{array}{l}8 \\
4 \\
2 \\
0\end{array}$ & $\begin{array}{l}33 \\
25 \\
29 \\
16\end{array}$ \\
\hline $\begin{array}{l}\text { Both series: } \\
\text { Controls .. } \\
\text { Linoleate group }\end{array}$ & $\begin{array}{l}24 \\
33\end{array}$ & $\begin{array}{r}38 \\
4\end{array}$ & $\begin{array}{r}10 \\
4\end{array}$ & $\begin{array}{l}62 \\
41\end{array}$ \\
\hline
\end{tabular}

Serum Fatty Acid Levels. - Although we had shown earlier that the daily administration of sunflower seed oil supplements over a five-day period resulted in a significant rise of the serum linoleate level both in healthy subjects and in patients with multiple sclerosis (Belin et al., 1971), it was decided to study the serum fatty acid levels over a more prolonged period in order to determine to what extent sustained alterations in the serum fatty acid levels were produced in the patients taking part in the trial. The fatty acid composition of the serum lipids was therefore determined in blood samples obtained from the London patients at intervals of two to three months for periods up to one year. The results are summarized in table VI, in which the levels of serum linoleate and oleate estimated at the time of entry to the trial-that is, before dietary supplementation had started-are compared with the levels found after the patients had been taking the supplements for periods of 3 to 5 months and 9 to 12 months. In the patients receiving the sunflower seed oil supplements on whom serum lipid analyses were carried out the mean serum linoleate level rose from a presupplementation value of $28.6 \%$ (linoleate expressed as a percentage of the total fatty acids) to a value of $35 \cdot 2 \%$ after 3 to 5 months and $36.3 \%$ after 9 to 12 months. The serum oleate levels in this group fell

TABLE VI-Mean Serum Linoleate and Oleate Levels ( \pm S.E. of the Mean) in Patients given Sunflower Seed Oil and Olive Oil Supplements. (Levels are expressed as \% of Total Fatty Acids)

\begin{tabular}{cll|c|c|c}
\hline & & $\begin{array}{c}\text { Presupplementation } \\
\text { Level }\end{array}$ & $\begin{array}{c}\text { Level after } \\
3-5 \text { Months }\end{array}$ & $\begin{array}{c}\text { Level after } \\
\text { 9-12 Months }\end{array}$ \\
\hline $\begin{array}{c}\text { Sunflower seed oil: } \\
\text { Serum linoleate }\end{array}$ & $\ldots$ &. & $28.6 \pm 1.0$ & $35.2 \pm 1.5$ & $36.3 \pm 1.4$ \\
$\begin{array}{c}\text { Serum oleate } \\
\text { Olive oil: }\end{array}$ &. &. & $28.5 \pm 0.9$ & $25.2 \pm 1.2$ & $24.3 \pm 1.1$ \\
Serum linoleate &. &. & $30.1 \pm 1.4$ & $30.5 \pm 1.3$ & $29.5 \pm 1.4$ \\
Serum oleate &. &. & $27.7 \pm 1.0$ & $29.2 \pm 1.5$ & $29.5 \pm 1.0$ \\
\hline
\end{tabular}

from a presupplementation value of $28.5 \%$ to $25 \cdot 2 \%$ after 3 to 5 months and $24.3 \%$ after 9 to 12 months. In general the patients on linoleate supplements showed a remarkable consistency in the increase of the serum linoleate level as estimated in the successive samples. One patient out of the 12 in this group on whom these analyses were carried out failed to show any rise in serum linoleate level, the values found in the successive samples being $28.4 \%$ (presupplementation), $30.8 \%, 26.4 \%$, $27 \cdot 1 \%$, and $26 \cdot 2 \%$. In the patients receiving the olive oil supplements, on the other hand, the values of both linoleate and oleate in the serum remained almost unchanged.

\section{Discussion}

The major difference detected in this trial was the greater severity of clinical relapses in patients taking oleate than in those receiving the linoleate emulsion. This trend was observed at both centres and was highly significant overall, although the Belfast data, when taken alone, did not quite reach conventional levels of significance because the overall trend was partly due to high relapse scores in a small number of patients receiving oleate. At both centres the relapses in the control (oleate) group also tended to be more long-lasting than in the linoleate group (table V). The numbers of patients in the two groups who spent a total time in relapse of less than 10 weeks or more than 10 weeks are shown in table VII together with the statistical evaluation of the difference between the groups.

TABLE VII-No. of Patients who spent a Total Time in Relapse of Less than 10 Weeks or More than 10 Weeks

\begin{tabular}{|c|c|c|c|c|}
\hline & & & Less than 10 Weeks & More than 10 Weeks \\
\hline Belfast $\left\{\begin{array}{l}\text { Linoleate. } \\
\text { Oleate }\end{array}\right.$ & $\because$ & & $\begin{array}{r}10 \\
5\end{array}$ & $\begin{array}{r}5 \\
10\end{array}$ \\
\hline London $\left\{\begin{array}{l}\text { Linoleate. } \\
\text { Oleate }\end{array}\right.$ & $\begin{array}{l}\cdots \\
\cdots\end{array}$ & . & $\begin{array}{r}10 \\
9\end{array}$ & $\begin{array}{l}0 \\
6\end{array}$ \\
\hline Both series $\left\{\begin{array}{l}\mathrm{L} \\
\mathrm{O}\end{array}\right.$ & & & $\begin{array}{l}20 \\
14\end{array}$ & $\begin{array}{r}5 \\
16\end{array}$ \\
\hline
\end{tabular}

Overall difference between the groups: $\mathbf{P}<0.025$.

Relapses were also less frequent in patients taking linoleate at both centres, but the differences were mainly due to a small number of individuals in the oleate treated group who had multiple relapses, and the observed variations could well be due to chance effects. Taking both centres together, disability 
status tended to deteriorate slightly less in patients given linoleate than in those receiving oleate supplements, but while this was observed in the Belfast patients it was not found in London. In view of this difference it is impossible to make any useful judgement on whether linoleate treatment is likely to slow deterioration in multiple sclerosis. At first sight it may seem clinically unlikely that a treatment could reduce the severity of relapse but not the overall rate of deterioration, but it must be remembered that the latter will also depend on the extent to which recovery from relapse has taken place. A lack of correlation between relapse severity and long-term effect could also occur if, for instance, the treatment reduced secondary abnormalities at the time of relapse, an analogy being cerebral oedema associated with infarction.

A complication in interpretation is that patients seen in London (particularly those in the control group) had relatively short disease histories. However, even if relapses tend to be more frequent and more severe in patients with short histories we think it unlikely that there would have been as large a difference in severity between the linoleate and oleate treated groups in London as was observed.

The serial fatty acid estimations in the group receiving linoleate confirm the earlier finding (Belin et al., 1971) that there is no defect in the absorption of linoleate, in the doses used, in patients with multiple sclerosis. Despite assurances to the contrary it is possible that the one patient who did not show a rise in the serum linoleate level did not regularly take the supplements.

The dose of linoleate supplement, in the form of a $50 \%$ emulsion, was chosen arbitrarily but has been shown to cause a significant rise of the serum linoleate level. On the other hand, the dose of olive oil taken by the control group was deliberately lower, only $15 \%$ in a similarly flavoured emulsion. It was not possible to tell from taking the emulsion which oil was being administered, and they were similar in appearance. Serial fatty acid estimations in the control patients (table VI) showed that the olive oil emulsion, in the doses used, did not bring about any significant change in the serum fatty acid levels. Because of the absence of any significant change in serum fatty acid levels as a result of oleate supplementation it is more likely, therefore, that the linoleate supplements afforded a measure of protection during the two years of the trial, rather than that the increased intake of oleate was responsible for the greater number and severity of the relapses in the control group.

Our thanks are due to the Multiple Sclerosis Society for grants in support of this work, the Medical Research Council for their interest and advice in the initiation and design of this trial, and Macarthys Laboratories Ltd. for the preparation of the vegetable oil emulsions. We also wish to thank the pharmacy staif of the two hospitals for their help.

\section{References}

Alling, C., Vanier, M.-T., and Svennerholm, L. (1971). Brain Research, 35, 325.

Allison, R. S. (1963). Proceedings of the Royal Society of Medicine, 56, 71 Arnetoli, G., Pazzagli, A., and Amaducci, L. (1969). Fournal of Neuro-

chemistry, 16, 461.
Baker, R. W. R., Thompson, R. H. S., and Zilkha, K. J. (1963). Lancet, 1,26 .

Baker, R. W. R., Thompson, R. H. S., and Zilkha, K. J. (1964). Fournal of Neurology, Neurosurgery and Psychiatry, 27, 408.

Belin, J., Pettet, N., Smith, A. D., Thompson, R. H. S., and Zilkha, K. J. (1971). Fournal of Neurology, Neurosurgery and Psychiatry, 34, 25.

Caspary, E. A., Prineas, J., Miller, H., and Field, E. J. (1965). Lancet, 2, 1108 .

Clausen, J., and Hansen, I. B. (1970). Acta Neurologica Scandinavica, 46, 1 Cumings, J. N., Shortman, R. C., and Skrbic, T. (1965). Fournal of Clinica Pathology, 18, 641 .

Gerstl, B., Kahnke, M. J., Smith, J. K., Tavaststjerna, M. C., and Hayman, R. B. (1961) Brain, 84, 310 .

Gerstl, B., Eng. L. F., Tavaststjerna, M., Smith, K. J., and Kruse, S. L. (1970). Fournal of Neurochemistry, 17,677.

Gul, S., Smith, A. D., Thempson, R. H. S., Wright, H. P., and Zilkha K.'J. (1970). Fournal of Neurology, Neurosurgery and Psychiatry, 33, 506.

Kurtzke, J. K. (1961). Neurology, 11, 686

Mahler, R. (1971). Unpublished observations.

Millac, P. (1967). Zeitschrift für Nervenheilkunde, 191, 74

Millar, J. H. D., Merrett, J. D., and Dalby, A. M. (1966). Fournal of Neurology, Neurosurgery and Psychiatry, 29, 187.

Millar, J. H. D., Vas, C. J., Noronha, M. J., Liversedge, L. A., and Rawson, M. D. (1967). Lancet, 2, 429.

Payling Wright, H., Thompson, R. H. S., and Zilkha, K. J. (1965). Lancet, 2,1109 .

Sanders, H., Thompson, R. H. S., Payling Wright, H., and Zilkha, K. J. (1968). Fournal of Neurology, Neurosurgery and Psychiatry, 31, 321.

Sinclair, H. M. (1956). Lancet, 1, 381.

Swank, R. L. (1950). American fournal of the Medical Sciences, 220, 421. Swank, R. L. (1970). Archives of Neurology, 23, 460.

Thompson, R. H. S. (1973). Biochemical Society Symposium No. 35

Tichy, J., Vymagal, J., and Michalec, C. (1969). Acta Neurologica Scandinavica, 45, 32 .

Wright, H. Payling (1941). fournal of Pathology and Bacteriology, 55, 255.

\title{
Observations on the Epidemiology of Simple Hypospadias
}

\author{
C. J. ROBERTS, S. LLOYD
}

British Medical fournal, 1973, 1, 768-770

\section{Summary}

A descriptive epidemiological study of simple hypospadias-that is, hypospadias without coexisting malformation outside the genital system-in a birth population of 46,927 singleton males and 1,013 twin males showed that the condition was significantly more common $(P<0.001)$ in uniovular twin males than in either singleton or binovular twin males. Also the temporal distribution of dates of conception had a significant cyclic pattern for each year of the study. Both observations are thought to support the view that gonadotrophin levels at stage 3 sexual organogenesis play an important part in normal masculinization of male external genitalia.

Department of Social and Occupational Medicine, Welsh National School of Medicine, Cardiff CF4 4XN

C. J. ROBERTS, M.D., PH.D., Senior Lecturer

S. LLOYD, B.SC., Scientific Officer

\section{Introduction}

Although the general attitude of the paediatrician has been to regard simple hypospadias as mainly a problem of reconstructive surgery (Aarskog, 1970), there is evidence from workers in experimental embryology, cytogenetics, steroid biochemistry, and neonatal pathology that its importance may be greater than has been hitherto realized. Experiments by Jost (1948, 1965, 1966) in rabbits have shown that the effects of an impairment of testicular function during fetal life depend on two factors: the stage of sexual differentiation at which the impairment is operative-that is the age of the fetus-and the degree of testicular impairment. Bilateral castration of a gonadal male fetus at an early stage results in an entirely female phenotype, whereas impairment of testicular secretory activity at a later stage (produced by decapitation of the fetus) results in hypospadias. Accordingly Jost and others (Campbell, 1963) regarded hypospadias as a mild form of pseudohermaphroditism, the latter being a condition where the gonad is a testis, but in which there are either gross remnants of the Müllerian structures or the appearance of the external genitalia is ambiguous.

In man, the situation is complicated by the fact that the 